\title{
A Mire of Discount Rates: Delaying Conservation Payment Schedules in a Choice Experiment
}

\author{
Ioanna Grammatikopoulou ${ }^{1,2}$ (D) $\cdot$ Janne Artell ${ }^{1} \cdot$ Turo Hjerppe $^{3} \cdot$ Eija Pouta $^{1}$
}

Accepted: 4 September 2020 / Published online: 19 September 2020

(c) The Author(s) 2020

\begin{abstract}
Studies on the public's implicit discount rate in the willingness to pay for environmental amenities have mostly employed contingent valuation surveys. We investigate respondents' time preferences using choice experiments with four payment schedules in a split-sample design in the context of mire conservation. We first examine preference and taste heterogeneity among respondents, finding them to a large extent independent of payment schedules. Next we use an endogenous approach to jointly estimate the implicit discount rates and preferences using choice experiments data. We explore exponential and hyperbolic discounting model specifications. We find insensitivity to the length of the payment period and support for hyperbolic discounting. Furthermore, we provide policy relevant valuation results concerning mire conservation.
\end{abstract}

Keywords Exponential discounting $\cdot$ Hyperbolic discounting $\cdot$ Choice experiment $\cdot$ Mixed logit model

\section{Introduction}

Stated preferences studies require respondents to trade between flows of benefits and costs. The role of these flows in valuation and decision making is exacerbated when assessing benefits related to conservation measures. Perceived and actual conservation benefits accrue relatively slowly after measure implementation compared to costs, which are typically borne immediately. Such tradeoffs require valuation survey respondents intertemporal choice making thus including time preferences in the valuations. Time preferences are manifested in cost-benefit analysis by the choice of a discount rate. The economic feasibility of a lengthy environmental restoration or conservation project with immediate (opportunity) costs and a slow flow of benefits over time is sensitive to the choice of discount rate (Vasquez-Lavin et al. 2019) and its form. While the appropriate social discount rate

Ioanna Grammatikopoulou

ext.ioanna.grammatikopoulou@luke.fi

1 Natural Resources Institute Finland (Luke), Helsinki, Finland

2 Global Change Research Institute of the Czech Academy of Sciences, Brno, Czech Republic

3 Finnish Environment Institute, Helsinki, Finland 
in cost-benefit analysis of intergenerational policy effects is a topic of discussion in itself (Freeman and Groom 2014; Groom et al. 2005), the discount rate and its form implicitly or explicitly expressed by the current generation remains an area with relatively few empirical examples.

In valuation context the public's discount rate has been studied by altering the time schedule for providing the good or the payments. The typical approach in analysing the effect of a payment schedule on willingness to pay, or the embedding effect in timing, has been to compare a lump-sum payment with some series of payments (Table 8, "Appendix"). The typical series include annual payments for ten years and an intermediate time period, while a group of studies (Brouwer et al. 2008; Kim and Haab 2009; Egan et al. 2015) have also tested perpetual payments. Previous stated preference valuation studies-contingent valuation and choice experiment studies have found implicit discount rates ranging between 20 and 270\% (Table 8, "Appendix"). A direct comparison between the prior studies is challenging due to the difference in the valued environmental good and time schedules of the proposed change. However, it appears that willingness to pay (WTP) per payment occasion is rather insensitive to the number of payment occasions, i.e. the total WTP increases as a function of the presented number of payment occasions.

Egan et al. (2015) recently called for investigation into how consumers consider payments in different settings and time horizons. Our study takes the challenge considering the effect of a varying payment schedule on a population level in connection with long-term environmental change in a mire conservation setting using choice experiments (CE).

We focus on ecosystem services provided by mires in southern Finland up until the year 2050. Mire conservation produces a slowly increasing flow of benefits under natural processes, where conservation costs are borne up front via compensated voluntary and involuntary land acquisitions. This feature provides a possibility to analyse whether small delays in the payment schedule affect WTP while credibly maintaining the expected realization time of environmental outcomes. Delays in payment schedule may affect the stated preferences for mire protection attributes. Further, the setting allows analysing if taste heterogeneity changes by the payment schedule.

Prior studies have commonly employed a constant discount rate over time, or exponential discounting. In the context of nature conservation this assumption suppresses values in the distant future (Vasquez-Lavin et al. 2019). Previous studies have demonstrated that consumers show signs of hyperbolic discounting, i.e. a 'present bias' where the discount rate decreases over time (Lew 2018). This behavior implies a lower discount rate for the far future than the near future. In other words, hyperbolic discounting behavior is more impatient (i.e. discount values heavily) for immediate benefit-cost tradeoffs but has more patience for benefit-cost tradeoffs that occur far in the future (Meyer, 2013a). In project evaluation, compared to exponential discounting, hyperbolic discounting behavior increases the importance of values accruing over a long run in decision making (Karp 2005; Karp and Tsur 2011). In this paper we explore both exponential and hyperbolic specifications of discounting.

For measuring discount rates in stated preferences studies two approaches have been employed; an exogenous, or external approach (as in Viscusi et al. 2008 and Egan et al. 2015; Wange and He 2018), and an endogenous, or internal one (as in Bond et al. 2009; Andersson et al. 2013; Lew 2018). In the exogenous approach the discount rate is calculated outside the valuation model, while in the endogenous approach the discount rate is directly estimated within the valuation model by using sample-level variation in the benefits or the payment horizon. 
We use the endogenous approach to jointly estimate the implicit discount rates and preferences using choice experiment data. We explore the discount rate varying the payment schedule across the sample where payments are specified as either lump-sum payments of annual ten-year payments. To show the effect of delay of payments we propose respondents annual ten-year payments with three different time delays, i.e. 0, 3 and 6 years of delay. These treatments allow us to analyse the relative strength of the time-embedding effect in relation to understanding the role of payment timing in a more or less distant future period.

Our findings will enhance the rather limited literature regarding the effect of payments using choice experiment data. Most of the relevant past studies refer to contingent valuation applications. By exploring whether a discount rate can be jointly estimated in choice modelling we aim to contribute to the discussion mainly raised in Egan et al. (2015) and Lew (2018) regarding the use of lump-sum vs annuals streams of payments. Also, by incorporating variation in the delay of payments we will explore whether the payment schedule follows a certain form of discounting. To the best of our knowledge this is the first study in $\mathrm{CE}$ literature that investigates this. Unlike prior studies, we study the discount rates by time schedule treatments with a split sample design rather than looking at individual consumers' time preferences. This makes our approach free of individual level survey anchoring effects in the time preference elicitation. Finally, we provide an addition to the literature on discount rates and welfare estimates for the conservation of northern European mire ecosystem services, filling an essential knowledge gap.

We next describe the case study, data collection and choice experiment and the design of time-frame treatment in the data and methods section. The econometric models and discount rate calculation are explained in a respectively named section followed by the results and final discussion.

\section{Case Study Description}

Benefits from mire protection emerge over a long period of time. The implementation costs of a conservation program constitute mainly from land purchases and can be scheduled either in the very beginning of implementation or they can take place during a longer time period of land acquisition. This feature of the conservation program provides a natural setting to test the effect of payment scheme on willingness to pay.

Originally over a quarter of the nation's land area, the majority of mires in Finland have been drained for forestry (Metsähallitus, State Forest Enterprise 2016). Mires have also been cleared and drained for peat extraction and, to a smaller degree, agricultural use. Concerns over self-sufficiency and the political impetus for bioeconomy-based economic growth (Prime Minister's Office 2015) have increased pressure to expand the use of peat as an energy source. Due to exhausting production areas, just maintaining the current peat use in energy production will require tripling of the production area, currently about $400 \mathrm{~km}^{2}$, to $1200 \mathrm{~km}^{2}$ by 2050 .

The utilization of non-market ecosystem services from mires is in direct conflict with most economic activities. Draining typically deteriorates, and peat extraction essentially shuts down the functioning of mires as a habitat for animal and plant species, and also hinders recreational activities (e.g. berry picking and hiking). Peat extraction areas release large amounts of carbon to the atmosphere. After extractive processes have ended, mires may restore naturally over a long time period. 
The most recent estimate in 2008 lists roughly $50 \%$ of the undrained mire areas in southern Finland as endangered and $40 \%$ as near threatened biotopes (Kaakinen et al. 2008). Despite considering the current conservation areas inadequate, in late 2014, the Finnish Ministry of the Environment postponed a prepared update to the mire protection programme, the Complementing Mire Protection Programme (CMPP). The CMPP aimed at conserving biodiversity by protecting spatially connected areas with high natural values. The focus of the legislator shifted from government-enforced actions to favouring voluntary mire conservation by private land owners. As there is inherent uncertainty in the success of a voluntary programme, we study mire protection scenarios that are better and worse than the goals of the original CMPP.

\section{Choice Experiment Design and Data Collection}

\subsection{Defining the Attributes and Their Levels}

We used the CICES classification (CICES 2016) of ecosystem services to identify the set of ecosystem services enhanced by mire conservation. After an initial expert screening of relevant ecosystem services, we arranged a layman focus group discussion to highlight the most important services to be used as attributes in a choice experiment. This process led to identification of five attributes that describe the effects of mire protection: climate effects and carbon storage, mire species diversity, water quality, the area of mires suitable for berry picking, and a change in the level of peat production and the share of domestic fuels in national energy production (Table 1). The last attribute takes into account the effect of peat production on local employment and energy self-sufficiency.

To determine realistic attribute descriptions and levels, we used expert advice and GIS analyses to construct a baseline scenario for the year 2050. This was a peat-based bioeconomy scenario, where annual peat extraction would be increased by $30 \%$ from its current level, mostly targeting unprotected peatland areas, but also some areas with a high natural value if profitable. The other end of the range of attribute levels was obtained from a conservation programme in which peat extraction would decrease by $30 \%$ and economic activities would only focus on previously drained mires. These scenarios provided the attribute level ranges (see Sect. 3.3 Implementation of the CE).

\subsection{Design of the Choice Tasks}

Attribute levels for the choice tasks were allocated using an efficient experimental design in the choice experiment survey (Rose and Bliemer 2009). Generating an efficient design requires specifying priors for the parameter estimates. The pilot survey design was constructed with uninformed priors, where parameter estimates from the pilot study provided priors for the final experimental design. This was a Bayesian D-efficient design using Ngene (v. 1.0.2) software, taking 500 Halton draws for the prior parameter distributions. ${ }^{1}$ We generated 36 choice tasks, blocked into 6 subsets, resulting in six choice situations for each respondent.

${ }^{1}$ D-error 0.097854. 


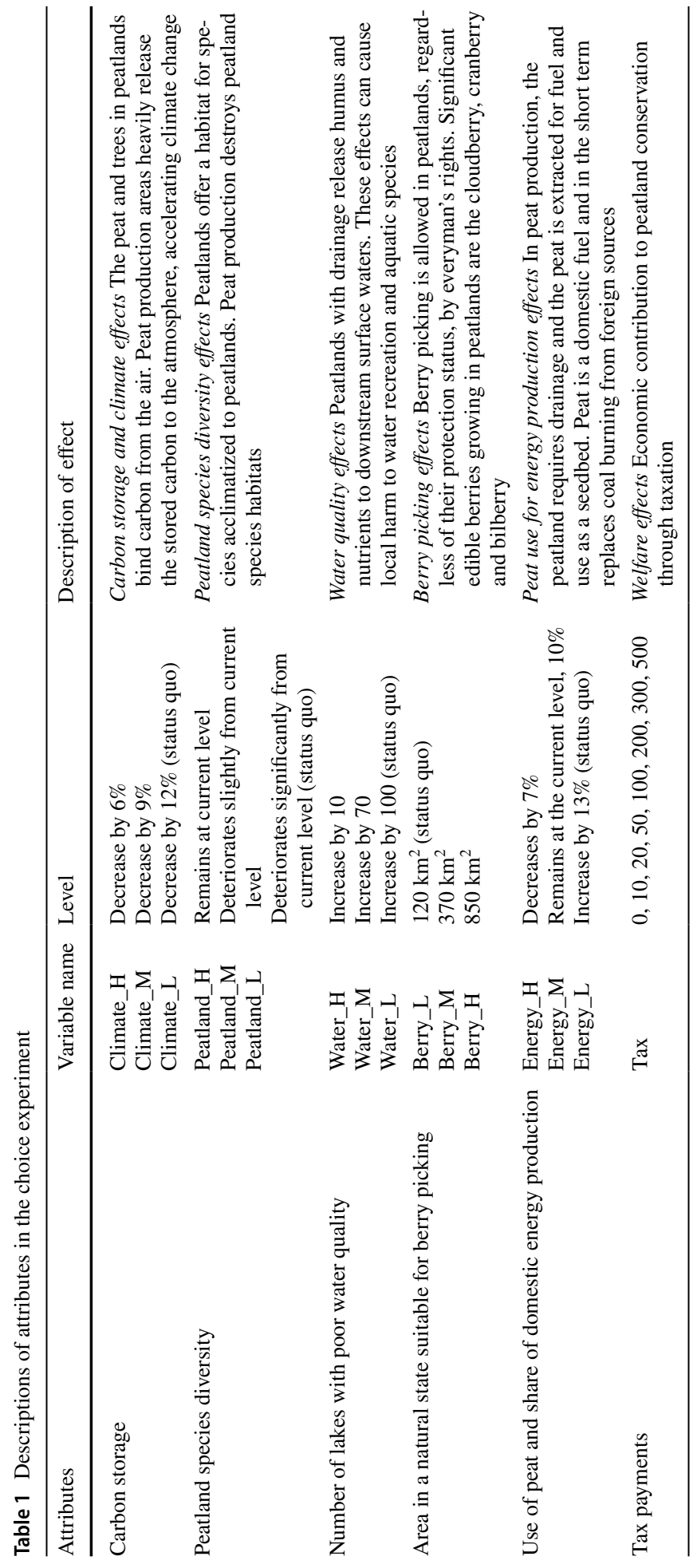




\subsection{Implementation of the CE}

The choice situation was introduced to survey respondents explaining the alternatives for mire use in southern Finland. Survey respondents were motivated with a note stating that the information acquired would help decision-makers to guide the future use of peatlands in Finland. Each choice task was also preceded by a reminder on the personal budget constraint, alternate uses of money including other forms of nature protection, and on the time scale of the effects, beginning to form in 2017 and reaching their full extent in 2050.

Table 2 provides an example of a choice set, where option Y includes the best environmental state for each attribute and the lowest peat production level, and option $\mathrm{Z}$ an intermediate level for each attribute. The current development has the worst environmental state for each attribute and the highest peat production level.

\subsection{Payment Schedule Treatment}

We tested four payment schedules with independent split samples to avoid having individual respondents anchoring or adjusting their stated preferences to multiple payment schedules. An equal number of respondents were allocated to each split sample. The split sample design implies that the time preferences are observed at a population level instead of individual level. The payment schedule subsamples were as follows:

1. Lump-sum payment: a single payment in 2017

2. 10-years annual payment (total sum informed) starting in 2017 and lasting until 2026

3. 10-years annual payment (total sum informed) starting in 2020 and lasting until 2029

4. 10-years annual payment (total sum informed) starting in 2023 and lasting until 2032

The lump-sum payment varied between $0,10,20,50,150,200$ and 500 euros. The same scale was used for annual payments in subsamples 2, 3 and 4, implying accumulating payments of up to $€ 5000$ over ten years. The total sums were shown to respondents as suggested by Egan et al. (2015). For the lump-sum payment, respondents were reminded that the single payment would cover the whole policy period.

\subsection{Data Collection}

The choice experiment attributes were tested in a focus group meeting and the collected experience helped to clarify and sharpen the questionnaire. The survey questionnaire was tested on a pilot sample of 204 respondents. The final survey was gathered between August and October 2016 as an internet survey from a respondent panel to ensure a nationally representative sample for the survey. The internet panel by Taloustutkimus Oy comprised over thirty thousand respondents recruited to the panel using random sampling to represent the population (Taloustutkimus 2017). The invitation e-mail that was sent to respondents did not reveal the topic of the survey but informed them about the possibility of obtaining a prize. From the contacted panel members $71 \%$ did not start responding the survey and $11 \%$ interrupted either immediately or during the survey. It was challenging to obtain respondents especially from younger panellists who are reluctant to respond to longer and more demanding surveys and who tended to interrupt responding. After five reminders, 1997 


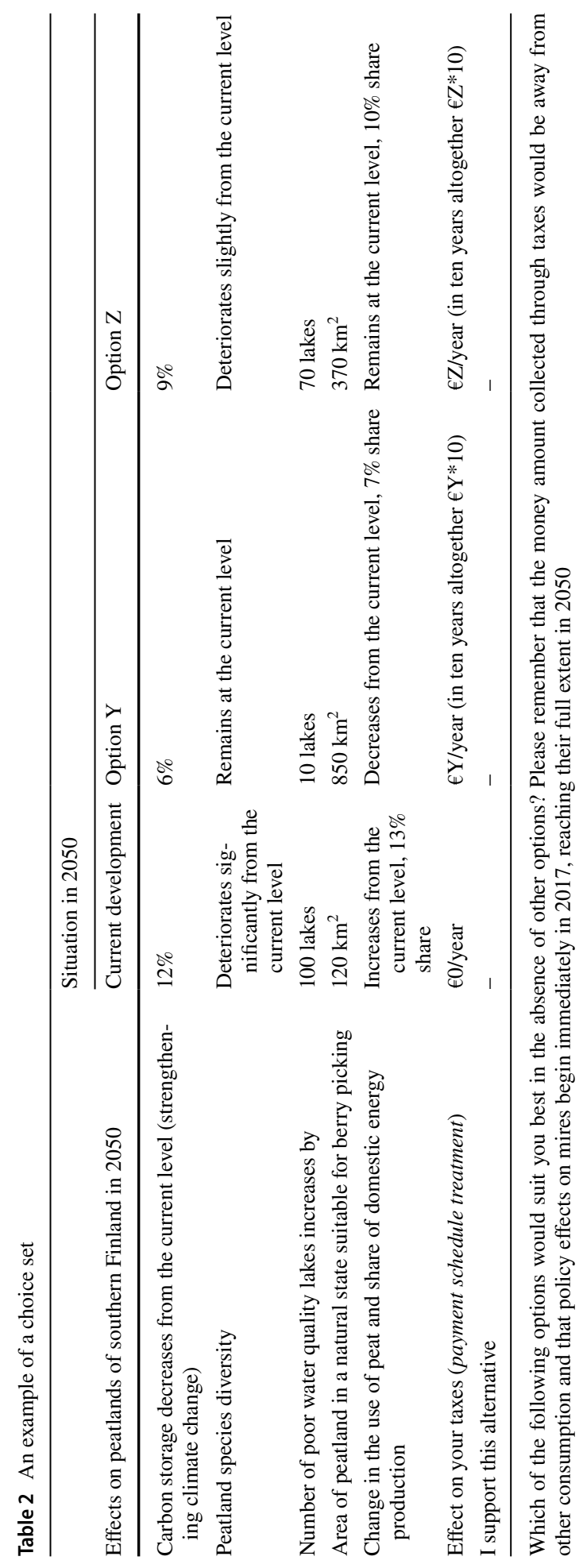


Table 3 Descriptive statistics for the full sample

\begin{tabular}{lll}
\hline Socio-demographic variables & Sample & Population \\
\hline Age (mean) & 52.2 & $42.0^{\mathrm{a}}$ \\
Gender (\% males) & 54.7 & $49.3^{\mathrm{a}}$ \\
Educational level (college or higher, \%) & 56.8 & $32.5^{\mathrm{a}}$ \\
Household size (equal to or lower than 2 members, \%) & 70.4 & $75.8^{\mathrm{a}}$ \\
Median annual household income (gross, $€$ ) & $40000-50000$ & $43780^{\mathrm{b}}$ \\
\hline
\end{tabular}

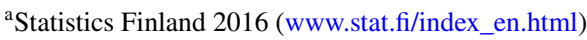

${ }^{\mathrm{b}}$ Statistics Finland 2015

respondents completed the whole survey, giving a response rate of $18 \%$. The response rate, although low, was higher than the average (13\%) for the panel. Table 3 presents descriptive statistics for the final data showing overrepresentation by males, an older population with above-average education and income, and underrepresented by the population with larger households. There were essentially no statistically significant differences across the payment schedule treatment groups by age, region, gender, income or education level. ${ }^{2}$

\section{Econometric Models and Welfare Estimates}

\subsection{Mixed Logit with Interactions Model}

Preference heterogeneity can be modelled by employing a mixed logit model (Mc Fadden and Train 2000; Train 1998, 2003; Hensher and Greene 2003). The model reveals preference variation both in terms of unconditional taste heterogeneity (random heterogeneity) as well as conditional heterogeneity (systematic heterogeneity) where individual characteristics or other factors of interest interact with choice-specific attributes and/or with the alternative specific constant (ASC) (Train 2003; Hensher et al. 2015). A mixed logit model with interactions (McFadden and Train 2000; Train 1998) is employed in case of a priori assumptions regarding the sources of heterogeneity. In this paper we investigate whether preferences are affected by the version of payment schedule. Hence, we first explore a mixed logit with interactions model where all attributes (including the ASC) interact with the four payment versions of the choice experiment.

The random utility theory (Mc Fadden 1974) is the baseline framework for modeling individual preferences within the choice experiment context. The framework suggests that each respondent faces a set of mutually exclusive alternatives, $j=1,2, \ldots, J$. The level of respondents' utility $U_{j}$ that is obtained from each alternative is decomposed into the deterministic part $V_{j}$ and the unobserved part $\varepsilon_{j} \forall j$ which is considered random. $V_{j}$ is linear in the $k$ observable attributes $x_{j}$ and payment $A_{j}$ [Eq. (1)].

\footnotetext{
${ }^{2}$ Chi-square tests reveal significant difference ( $p$-value 0.05) across versions in education-version 2 subsample has $8.8 \%$ respondents with comprehensive school level compared to version 3 sub-sample's $7.4 \%$.
} 


$$
U_{n j}=V_{n j}+\varepsilon_{n j}=\sum_{k} \beta * x_{n k j}+\gamma * A_{n j}+\varepsilon_{n j}
$$

Accounting for heterogeneity, the utility model includes two additional terms; the term $\delta_{n} * x_{j}$ that aims to capture random taste among individuals and $\mu_{m} * p_{m}$ that captures the systematic heterogeneity around each attribute (and/or ASC) which here is associated with payment version $p$, thus interacting with each attribute $x$. The utility for any individual $n$ is specified as:

$$
U_{n j}=\sum_{k} \beta * x_{n k j}+\delta_{n} * x_{n k j}+\sum_{k} \sum_{m} \mu_{m} * p_{m} * x_{n k j}+\gamma * A_{n j}+\varepsilon_{n j}
$$

Equation (2) can be rewritten in a comparable form to the standard conditional logit by substituting $b_{n}=\beta+\delta_{n}$, implying that the coefficients may now vary randomly across individuals $n$. Since the coefficient vector $b_{n}$ is not observed, we may assume that it follows a distribution with density $f\left(b_{n}\right)$. The mixed logit probability of choosing alternative $j$ is a weighted average of the logit formula evaluated at different values of $b$ with the weights given by the density $f(b)$. The model assumes that the mixing distribution is continuous and $b$ follows a normal, log-normal, uniform, triangular, gamma or any other distribution (Hensher et al. 2015). Choice probabilities are the integral of standard logit probabilities over a density of parameters

$$
P_{n j}=\int \frac{\exp \left(x_{n j} b_{n}^{\prime}\right)}{\sum_{j=0}^{J} \exp \left(x_{n j} b_{n}^{\prime}\right)} f(\beta) d \beta
$$

The integral has no analytical solution but can be approximated by simulation. One must make assumptions about how $b$ coefficients are distributed over the population, take a set of $\mathrm{R}$ draws and then calculate the logit probability for each draw.

\subsection{Discount Rate Estimation Models and Econometric Specifications}

The present value $(P V)$ of payment $A$ is estimated using a non-linear specification of the discount formula. Here we investigate two forms of discounting, i.e. an exponential form and a hyperbolic one. ${ }^{3} P V$ is the sum of T discounted payments of size $A$ which begin at time $\mathrm{t}=0$ and finish at time $\mathrm{T}-1$ for all model specifications. $P V$ is estimated according to the anticipated discount formula:

a. In case of exponential discounting the $P V$ is:

$$
P V=\left[\sum_{t=0}^{T-1} A * \frac{1}{(1+\rho)^{t+D}}\right]=A *\left(1+\frac{1}{\rho}\right) *\left(1-\frac{1}{(1+\rho)^{T}}\right) *\left(\frac{1}{(1+\rho)^{D}}\right)
$$

b. in case of a Mazur hyperbolic discounting (Mazur 1987) the $P V$ is:

\footnotetext{
3 We also tried to explore a quasi-hyperbolic model so as to estimate the present bias parameter. Our model outcome showed a small bias parameter implying a strong present bias. Though, the discount rate parameter was negative and when restricted to be positive (by using an exponential expression) was found close to zero and outside $95 \%$ confidence intervals (questioning hence model convergence). This is a counterintuitive result that we cannot interpret.
} 


$$
P V=\left[\sum_{t=0}^{T-1} A * \frac{1}{1+\omega *(t+D)}\right]
$$

c. and under Harvey hyperbolic discounting (Harvey 1986) the $P V$ is:

$$
P V=\left[\sum_{t=0}^{T-1} A *\left(\frac{1}{1+(t+D)}\right)^{\mu}\right]
$$

where $\rho, \omega$ and $\mu$ and $D$ denote the discount rate parameters and the delay of payments, respectively.

The exponential formula implies constant discount rates whereas the hyperbolic specifications imply discount rates that decline as the discounted event is moved further away in time (Loewenstein and Prelec 1992). Outcomes in the near future are discounted at a higher implicit rate than events in the distant future. To estimate the instantaneous discount rates at time $t$ we used the following formula:

$$
\frac{-f^{\prime}(t)}{f(t)}
$$

where $f(t)$ is the discount formula in each model specification. For exponential discount formula, the discount rate is constant and is represented by a constant rate equal to $\mathrm{ln}$ $(1+\rho)$. For Mazur and Harvey hyperbolic formulas the instant rate declines with time and corresponds to $\frac{\omega}{1+\omega * t}$ and $\frac{\mu}{1+t}$ respectively.

The data are analysed using a non-linear mixed logit model that extends the utility function beyond the linear specification. The corresponding utility is then:

$$
U_{n j}=V_{n j}+\varepsilon_{n j}=\sum_{k} b * x_{n k j}+\gamma * P V+\varepsilon_{n j}
$$

Each model specification incorporates all environmental attributes (Table 1), the implicit discount rate $r$ as well as an alternative specific constant (ASC) that takes the value of one when the status quo choice is selected and zero otherwise. All environmental attributes are coded by applying effects-coding so as to avoid misinterpretation of estimates and correlation problems with ASC (Bech and Gyrd-Hansen 2005; Hensher et al. 2015). With the exception of the payment variable and the discount rate, all parameters are specified random under a normal distribution. The latter specification facilitates the calculation of WTP estimates. As WTP from a mixed logit model is given by the ratio of two random distributions, the resulting WTP distribution has infinite moments and, hence, poorly defined mean and standard deviation (Czajkowski et al. 2016). Parameter estimates of the mixed models are based on simulation. To reduce computation time, the estimations were performed using intelligent draws. All models were estimated using NLOGIT 6. Nonlinear mixed logit models were performed using 250 Halton draws while mixed logit with interactions models were performed using 500 Halton draws.

\subsection{Welfare Estimates}

The welfare change related to a hypothetical choice scenario can be estimated by using the compensating surplus (CS) measure, which corresponds to the amount of money that individuals must pay or accept, so that after the hypothetical change they can be as well off as 
Table 4 Probability of accepting the tax payment per version of the payment

\begin{tabular}{|c|c|c|c|c|c|}
\hline & $\begin{array}{l}\text { Lump-sum } \\
\text { payment (V1) }\end{array}$ & $\begin{array}{l}\text { Payment over } \\
10 \text { years/Starts in } \\
2017 \text { (V2) }\end{array}$ & $\begin{array}{l}\text { Payment over } \\
10 \text { years/Starts in } \\
2020 \text { (V3) }\end{array}$ & $\begin{array}{l}\text { Payment over } \\
10 \text { years/Starts in } \\
2023 \text { (V4) }\end{array}$ & Sig \\
\hline Payment & \multicolumn{5}{|c|}{ Probability of accepting the payment $(\%)$} \\
\hline 0 & 0.676 & 0.657 & 0.625 & 0.624 & 0.070 \\
\hline 10 & 0.590 & 0.613 & 0.580 & 0.579 & 0.437 \\
\hline 20 & 0.559 & 0.557 & 0.543 & 0.536 & 0.755 \\
\hline 50 & 0.342 & 0.336 & 0.318 & 0.361 & 0.320 \\
\hline 100 & 0.248 & 0.286 & 0.307 & 0.323 & 0.014 \\
\hline 200 & 0.223 & 0.245 & 0.251 & 0.262 & 0.448 \\
\hline 300 & 0.248 & 0.212 & 0.300 & 0.304 & 0.000 \\
\hline 500 & 0.248 & 0.292 & 0.256 & 0.273 & 0.293 \\
\hline
\end{tabular}

before the change. Given an increase in the quality of a public good, the CS is represented by the expected WTP, which can be derived by substituting the estimated parameters in the formula below (e.g. Colombo et al. 2009; Casey et al. 2008; Kosenius 2010; Birol et al. 2006):

$$
E(W T P)=-\frac{1}{\gamma} \sum b_{i}\left(x_{i}^{1}-x_{i}^{0}\right)
$$

where $b_{i} x_{i}^{1}$ and $b_{i} x_{i}^{0}$ represent the states before and after the change. The CS estimation was adjusted so as to account for the fact that all environmental attributes are coded using effects coding. In this case the reference point is defined as the negative sum of the estimated coefficients. For a change where all attributes are improved from a baseline state, i.e. low preservation level to a high preservation state the CS will be:

$$
E(W T P)=-\frac{\sum\left[b_{H, i}-\left(-b_{H, i}-b_{M, i}\right)\right]}{\gamma}
$$

where $b_{H, i}$ correspondents to the estimated parameter of attribute $i$ at high preservation state and $b_{M, i}$ at medium preservation state. The baseline state will be equal to the negative sum of both.

\section{Results}

\subsection{Descriptive Results}

Table 4 reports the probability of accepting an alternative choice according to the bid and payment schedule. Despite some noise around the tendency, the probability of accepting an offered bid or payment declined with higher offers. The probability of accepting a zero bid decreased with annual payments that extent in future. For the lump-sum payment version (V1), the proportion of acceptance reached a high of approximately $60 \%$ for $€ 10 / y e a r$ and a low of $22 \%$ for $€ 200 / y e a r$. For the majority of payments, the probability of acceptance did not differ statistically significantly across versions, and the same high and low percentages 
were noticed at corresponding payment levels. With the exception of $€ 100$ and $€ 300$ bids, the probability of acceptance didn't increase when prolonging the period of non-payment (V3 and V4). This baseline figure indicates signs of payment schedule insensitivity across subsamples.

The high \% proportion of 'Yes' responses for the highest bids (over 200) resulted in fat tails of payment distribution. Possibly this is due to the 'yea saying' phenomenon often observed in stated preferences surveys (Parsons and Myers 2016) but further investigation is out of the scope of this paper. To deal with this we replaced all values over $200 €$ with random numbers assuming a half normal distribution. The distribution is reported in Fig. 3 in "Appendix".

\subsection{Mixed Logit: Interactions with Payment Versions}

We first explored whether benefits differed by payment schedule. ${ }^{4}$ Table 5 reports the results of the mixed logit with interactions model where all attributes (except tax) interact with the different payment versions. The table is limited to show only the statistically significant estimates (for an extensive version see Table 9 in "Appendix"). Pseudo $\mathrm{R}^{2}$ value indicated an adequate performance of the model.

Almost all parameter coefficients were found statistically significant with values increasing alongside improved attribute levels. The ASC estimate was negative, suggesting higher utility from shifting away from the status quo, but possibly also indicating external factors playing a role in choices. The coefficient of tax payment was negative, as expected. Peatland diversity and quality of water were the attributes with the highest marginal utility when the conservation is attained at high level. We found for almost all attributes significant presence of heterogeneity. Hence all individuals within the sample could not be represented by the same sign for these attributes. The ASC, in particular, showed large dispersion calling for further exploration of heterogeneity.

The systematic heterogeneity around the mean values of model parameters could be explained by the time frame of payment but only for ASC and two CE attributes, i.e. peatland diversity and water quality. For the rest of CE attributes the interaction terms weren't found statistically significant. Therefore the benefit side of the valuation exercise could only be partially dependent on the payment side. For peatland diversity and water quality at high preservation state the expected welfare benefits would decrease in the case of annual payments and delay of payments. Also, heterogeneity in the mean parameter estimate of the interaction term of ASC with payment versions was found smaller for all annual versions compared to the lump sum one, suggesting that respondent would be more willing to shift from the status quo and choose a preservation option in case of annual payments than lump sum one. Though for delayed payments respondents' marginal utility for options away from current state would decrease since interaction terms estimates were found to be lower for V3 and V4 compare to V2. Hence, the welfare estimate for ASC would depend on the payment side.

\subsection{Discounting Models}

Table 6 reports the results of the mixed logit models given different specifications of the discount formula, i.e. exponential and hyperbolic (Mazur and Harvey). All models were

\footnotetext{
4 The survey respondents were informed that the stream of benefits start immediately in year 2017 where full benefits would occur by 2050 irrespective of the payment schedule split sample.
} 
Table 5 Mixed logit with interactions model

\begin{tabular}{|c|c|c|c|c|}
\hline Attributes & Coef.f & Std. error & Std. dev & Std. error \\
\hline $\mathrm{ASC}_{\mathrm{SQ}}$ & $-1.324 * * *$ & 0.362 & $4.326^{* * *}$ & 0.187 \\
\hline Climate_M & $0.192 * * *$ & 0.053 & 0.032 & 0.088 \\
\hline Climate_H & $0.202 * * *$ & 0.055 & $0.233 * * *$ & 0.066 \\
\hline Peatland_M & $0.203 * * *$ & 0.050 & $0.191 * *$ & 0.083 \\
\hline Peatland_H & $0.589 * * *$ & 0.069 & $0.539 * * *$ & 0.043 \\
\hline Water_M & 0.009 & 0.052 & $0.213^{* *}$ & 0.067 \\
\hline Water_H & $0.602 * * *$ & 0.061 & $0.409 * * *$ & 0.047 \\
\hline Berry_M & $0.140^{* *}$ & 0.057 & $0.313^{* * *}$ & 0.054 \\
\hline Berry_H & 0.110 & 0.069 & $0.440^{* * *}$ & 0.047 \\
\hline Energy_M & $0.099 *$ & 0.056 & 0.004 & 0.059 \\
\hline Energy_H & $0.226 * * *$ & 0.058 & $0.395^{* * *}$ & 0.047 \\
\hline Tax & $-0.006^{* * *}$ & 0.000 & - & - \\
\hline Interactions (V1 as reference) & \multicolumn{4}{|c|}{ Heterogeneity around the mean } \\
\hline $\mathrm{ASC}_{\mathrm{SQ}} \times \mathrm{V} 2$ & $-1.709^{* * *}$ & 0.463 & - & - \\
\hline $\mathrm{ASC}_{\mathrm{SQ}} \times \mathrm{V} 3$ & $-0.875^{*}$ & 0.466 & - & - \\
\hline $\mathrm{ASC}_{\mathrm{SQ}} \times \mathrm{V} 4$ & $-1.357 * *$ & 0.460 & - & - \\
\hline Peatland_H x V2 & $-0.166^{*}$ & 0.089 & - & - \\
\hline Peatland_H x V3 & $-0.195^{* *}$ & 0.089 & - & - \\
\hline Peatland_H x V4 & $-0.314 * * *$ & 0.089 & - & - \\
\hline Water_H x V2 & $-0.251^{* *}$ & 0.081 & - & - \\
\hline Water_H x V4 & $-0.162 *$ & 0.081 & - & - \\
\hline LL & -8703.081 & - & - & - \\
\hline AIC & $17,518.2$ & - & - & - \\
\hline $\mathrm{R}^{2}$ & 0.339 & - & - & - \\
\hline Sample size & 11,982 & - & - & - \\
\hline
\end{tabular}

The notation V1, V2, V3, V4 stands for payment version 1: lump sum, 2: 10 year annual no delay, 3:10 year annual 3 years delay and 410 year annual 6 years delay, respectively

$* * * 1 \%$ significance level, **5\% significance level, $* 10 \%$ significance level

statistically significant with a pseudo- $\mathrm{R}^{2}$ fit measure to be around 0.32 units across models. The exponential model specification showed the lowest model fit based on performance statistics (Akaike's Information Criterion (AIC), Bayes Information Criterion (BIC) and Log Likelihood (LL) estimates). Mazur specification fit data better than Harvey specification, but only marginally. For the latter, we estimated the relative likelihood value to compare the relative plausibility of Mazur and Harvey specifications. The relative likelihood value implied that Harvey model is 0,35 times as likely as the Mazur model to minimize the information loss.

Overall, the estimated parameters varied across different models but mainly only in magnitude. In all models a better state of CE attributes was associated with a higher marginal utility level with few exceptions, e.g. the area of berry picking. The ASC estimate found to be smaller when discount rate is assumed constant than at declining rate. The coefficient of tax parameters ranged from 0.001 to 0.003 where the exponential model specification showed smaller estimates than the hyperbolic specifications. This implies that under the assumption of a constant discount rate respondents seem less payment sensitive 
Table 6 Results of mixed logit models assuming different specifications of discount rate

\begin{tabular}{|c|c|c|c|c|c|c|}
\hline \multirow[b]{2}{*}{ Attributes } & \multicolumn{2}{|l|}{ Exponential } & \multicolumn{2}{|l|}{ Mazur } & \multicolumn{2}{|l|}{ Harvey } \\
\hline & Coeff & Std. error & Coeff & Std.error & Coeff & Std.error \\
\hline $\mathrm{ASC}_{\mathrm{SQ}}$ & $-1.085^{* * *}$ & 0.205 & $-1.356^{* * *}$ & 0.214 & $-1.339 * * *$ & 0.213 \\
\hline Climate_M & $0.150 * * *$ & 0.024 & $0.141 * * *$ & 0.024 & $0.141^{* * *} *$ & 0.024 \\
\hline Climate_H & $0.246^{* * * *}$ & 0.023 & $0.222 * * *$ & 0.023 & $0.222 * * *$ & 0.023 \\
\hline Peatland_M & $0.174 * * *$ & 0.023 & $0.166 * * *$ & 0.023 & $0.167 * * *$ & 0.023 \\
\hline Peatland_H & $0.543 * * *$ & 0.034 & $0.502 * * *$ & 0.034 & $0.501 * * *$ & 0.035 \\
\hline Water_M & 0.020 & 0.023 & 0.001 & 0.023 & 0.001 & 0.024 \\
\hline Water_H & $0.494 * * *$ & 0.030 & $0.469 * * *$ & 0.030 & $0.471 * * *$ & 0.030 \\
\hline Berry_M & $0.127 * * *$ & 0.026 & $0.104 * * *$ & 0.027 & $0.103 * * *$ & 0.027 \\
\hline Berry_H & 0.007 & 0.031 & 0.040 & 0.031 & 0.042 & 0.032 \\
\hline Energy_M & $0.123 * * *$ & 0.025 & $0.107 * * *$ & 0.026 & $0.106^{* * * *}$ & 0.026 \\
\hline Energy_H & $0.178 * * *$ & 0.027 & $0.155^{* * * *}$ & 0.028 & $0.153 * * *$ & 0.028 \\
\hline $\begin{array}{c}\text { Tax in present } \\
\text { value terms }\end{array}$ & $-0.001 * * *$ & 0.000 & $-0.003 * * *$ & 0.000 & $-0.003 * * *$ & 0.000 \\
\hline$\delta$ & $0.141 * * *$ & 0.021 & - & - & - & - \\
\hline$\omega$ & - & - & $1.309 * * *$ & 0.162 & - & - \\
\hline$\mu$ & - & - & - & - & $0.938 * * *$ & 0.054 \\
\hline \multicolumn{7}{|c|}{ Marginal discount rate } \\
\hline Year 1 & 0.132 & - & 0.567 & - & 0.469 & - \\
\hline Year 2 & 0.132 & - & 0.313 & - & 0.362 & - \\
\hline Heterogeneity & Std. dev & Std. error & Std. dev & Std. error & Std. dev & Std. error \\
\hline $\mathrm{ASC}_{\mathrm{SQ}}$ & $3.204 * * *$ & 0.146 & $3.296 * * *$ & 0.151 & $3.280 * * *$ & 0.150 \\
\hline Climate_M & 0.045 & 0.040 & 0.054 & 0.040 & 0.054 & 0.040 \\
\hline Climate_H & 0.069 & 0.046 & 0.074 & 0.046 & 0.074 & 0.046 \\
\hline Peatland_M & $0.124 * *$ & 0.044 & $0.139 * *$ & 0.043 & $0.139 * *$ & 0.043 \\
\hline Peatland_H & $0.469 * * *$ & 0.037 & $0.454 * * *$ & 0.037 & $0.456 * * *$ & 0.037 \\
\hline Water_M & $0.114 * *$ & 0.041 & $0.128 * *$ & 0.041 & $0.125 * *$ & 0.041 \\
\hline Water_H & $0.399 * * *$ & 0.044 & $0.409 * * *$ & 0.043 & $0.411^{* * * *}$ & 0.043 \\
\hline Berry_M & $0.254 * * *$ & 0.041 & $0.265^{* * *}$ & 0.040 & $0.263^{* * *} *$ & 0.040 \\
\hline Berry_H & $0.184 * * *$ & 0.052 & $0.185^{* * * *}$ & 0.052 & $0.188 * * *$ & 0.052 \\
\hline Energy_M & 0.021 & 0.054 & 0.032 & 0.056 & 0.029 & 0.055 \\
\hline Energy_H & $0.352 * * *$ & 0.039 & $0.335^{* * *}$ & 0.040 & $0.337 * * *$ & 0.040 \\
\hline LL & -8936.929 & - & -8902.349 & - & -8903.384 & - \\
\hline AIC & $17,921.9$ & - & $17,852.7$ & - & $17,854.8$ & - \\
\hline BIC & $18,099.3$ & - & $18,030.1$ & - & $18,032.2$ & - \\
\hline $\mathrm{R}^{2}$ & 0.321 & - & 0.324 & - & 0.324 & - \\
\hline Sample size & 11,982 & - & 11,982 & - & 11,982 & - \\
\hline
\end{tabular}

$* * * 1 \%$ significance level, **5\% significance level, *10\% significance level

that under the assumption of a decreasing rate. The estimated discount rate parameter was found statistically significant in all model specifications but of different magnitude, leading to different speculations on discounting. In the exponential model the discount rate 
parameter was $14 \%$ whereas in the hyperbolic models the estimate was $131 \%$ for Mazur specification and $94 \%$ for Harvey one.

In hyperbolic discounting future values decline heavily after $t=0$ but they don't reach zero in the long-run. The exponential discount specification prolonged the period of zero future values but that was because the discount rate found small in magnitude (if the model would result in high discount estimate then the importance of future values would be reduced to zero more rapidly, Groum et al. 2005).

Figures 1 and 2 illustrate how discount factors and discount rates are developed through time. At time $t=0$ the discount factors in all cases is 1 since individuals don't discount the present. Respondents would value only the present ignoring the payment specifics that is whether it is a lump sum or annual payments or whether annual payments are delayed. Later times are discounted heavily and the discount factor is almost zero. Assuming a constant discount rate the discount factor decreases smoothly and people would discount the utility received in 10 years at about $27 \%$ relative to the present. In case of a declining discount rate, the discount factor drops quickly after $t=0$, while after $t=4$ and $t=6$ the curves start to flatten out in Mazur and Harvey specification, respectively. The discount factors in year 10 were $10 \%$ and $7 \%$, respectively. Though, in a longer time perspective, constant discounting results to an almost zero discount factor while hyperbolic discount implies small but over zero discount factors. Hence, while individuals are impatient with near term tradeoffs, hyperbolic discount suggests that people become more patient and consider each increment in the distant future more than they would in case of constant discounting.

Marginal discount rates were estimated according to function 7 . The constant model suggested a flat rate of $13 \%$ annually. Hyperbolic models start with a high rate of 46-56\% which indicates a high degree of impatience from year 0 to year 1 , then in year 2 the rate drops in $32-36 \%$ and by the end of the period of payments $(t=10)$ the implied rate is

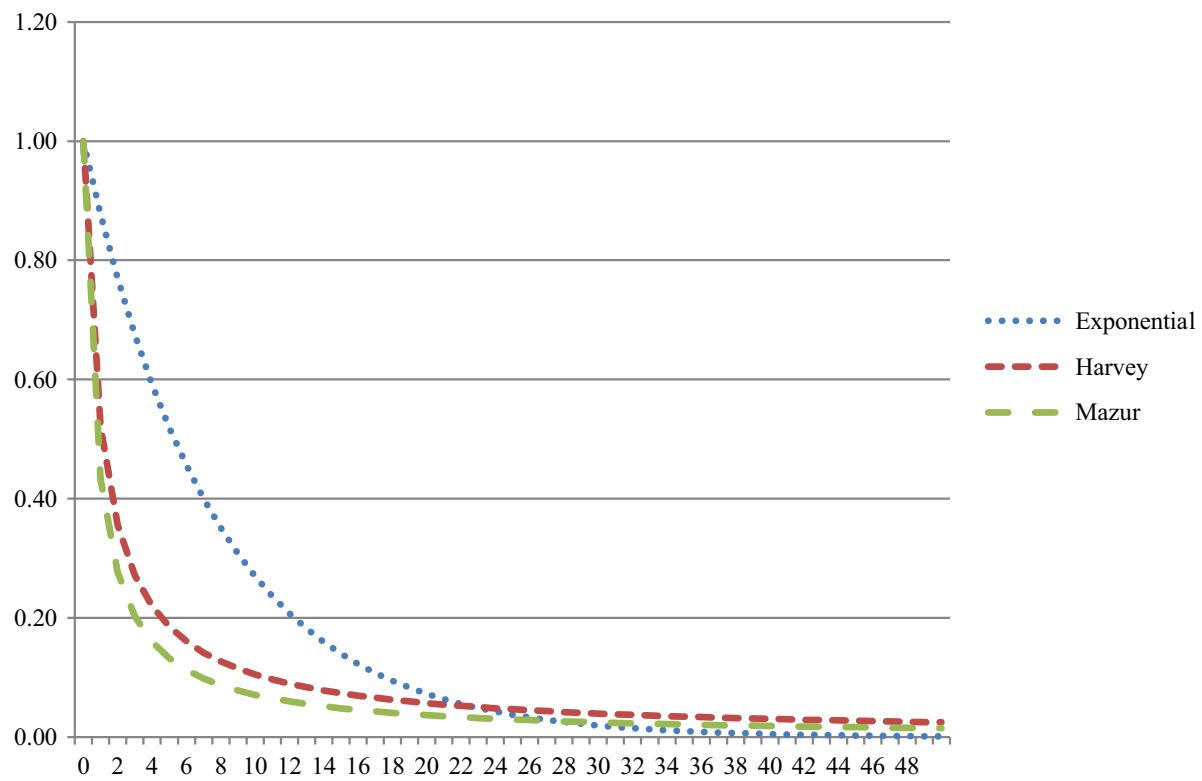

Fig. 1 Discount factors by year under different discount formulas and discount estimates 


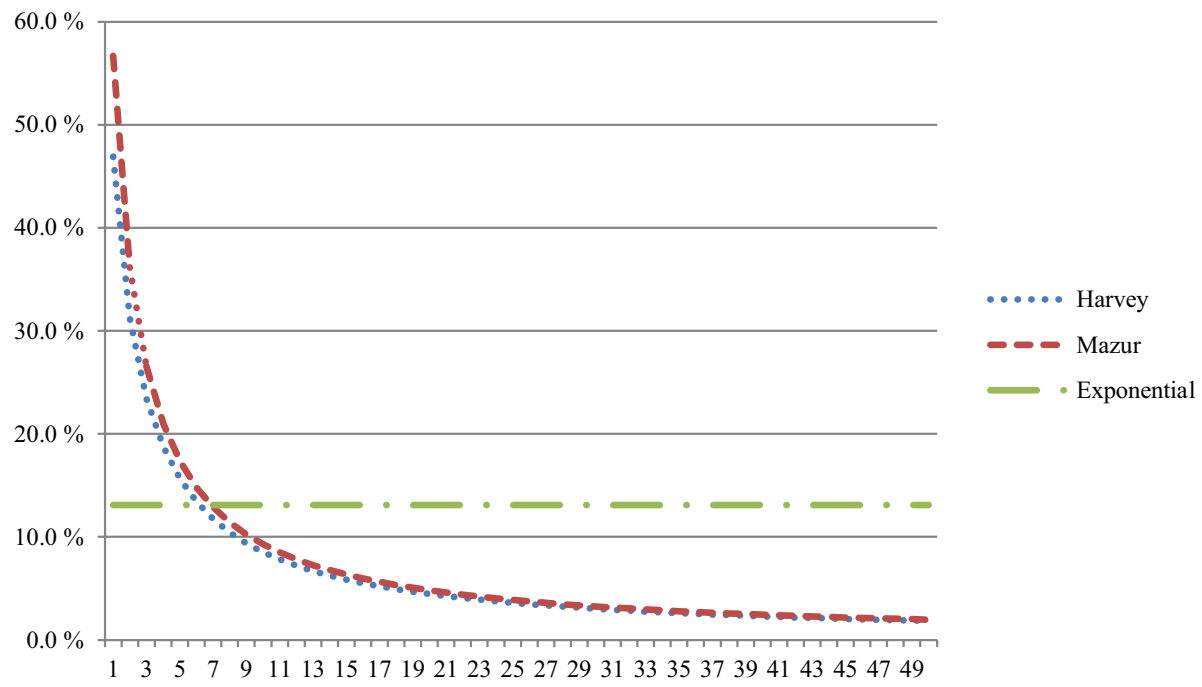

Fig. 2 Marginal discount rates by year under different discount formulas

below $9 \%$. For a longer-term horizon the rates decrease to almost $2 \%$. This is substantially lower than the constant rate.

\subsection{Estimates of Compensating Surplus}

Welfare analysis (Table 7) was specified for the baseline case that represents a policy orientation towards peat production and for two scenarios; scenario A and B where all environmental attributes are preserved at average and at the highest level, respectively. The baseline scenario was associated with negative CS in all model specifications and the welfare was improving when moving from baseline to either average or high preservation level. All model specifications suggested that a change from scenario A to B would reflect an increase in CS by almost $23 \%$.

The present value of welfare estimates variated across the anticipated discount models. The lowest CS was observed under hyperbolic Mazur specification model and the higher under constant discounting. For the best preservation case scenario (i.e. scenario B) exponential model provided an estimate close to $4117 €$ per respondent, whereas hyperbolic gave as much as $\mathbf{5 7 \%}$ lower estimates. This outcome is partly explained by the different payment coefficient and thus the different payment sensitivity that each model revealed. The exponential model showed the lowest payment sensitivity. Both hyperbolic models provide comparable estimates while their $95 \%$ confidence intervals were overlapping to some degree. The findings highlight that the choice of discounting is an important decision to be made in welfare analysis and results differentiate given the speculations around discounting specifics. 


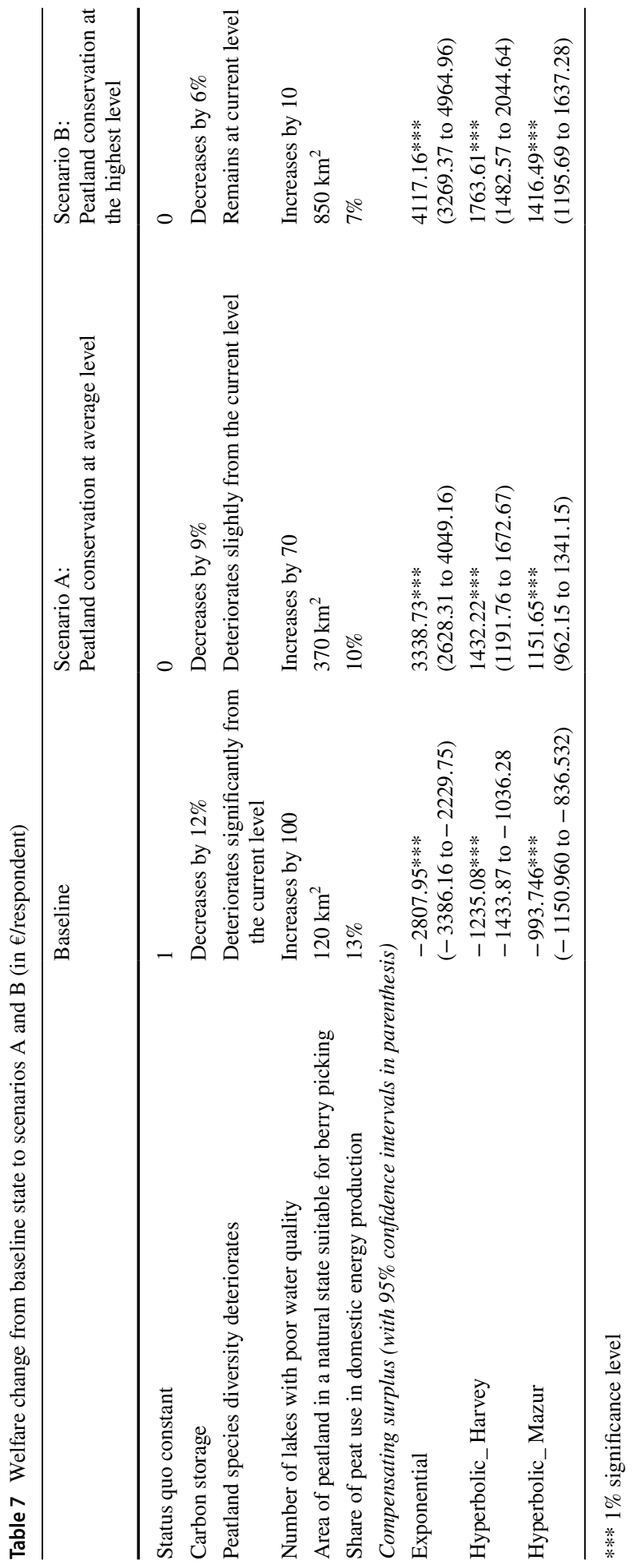




\section{Discussion and Conclusions}

We investigated the effect of different payment schedules for a long-term mire conservation project employing a choice experiment. The study sample was divided into four subsamples, where the payment schedule varied (a lump sum payment, a 10-years annual payment starting from 2017, a 10-years annual payment starting from 2020 and a 10-years annual payment starting from 2022) for each subsample. This split sample approach aimed to explore the time preferences at population rather than at individual level, avoiding hence individual survey induced anchoring effects on time preferences.

We first explored whether payment versions are associated with preference heterogeneity and as such whether benefits would differ under different payment schedules. Next we estimated the implicit rate of time preferences under alternative discount rate specifications jointly with CE data to measure preferences. We assumed the following specifications: an exponential and a hyperbolic one. The CE data were estimated with a mixed logit model that accounts for preference heterogeneity.

We found strong indications of taste heterogeneity while the time frame of the payment could partly explain this observed taste heterogeneity. For most of the environmental attributes preferences were detached from the payment schedule. This temporal insensitivity of welfare benefits is in line with respondents' choices that are anticipated independent of payment schemes (Kim and Haab 2009). Though for changing peatland diversity and water quality to a high preservation state welfare benefits would lessen in the case of payment delays affecting thus the welfare analysis estimates for the best case scenario (i.e. environmental attributes at the highest preservation state). Also we found strong heterogeneity in the mean of ASC parameter implying that respondents would better prefer to forgo status quo and choose a preservation option when payments are annual than lump sum ones.

Our model findings revealed important information for the conservation of northern European mire ecosystem services. The case showed that Finnish citizens are in favour of mire conservation with a focus on preserving habitat ecosystem services and avoiding the deterioration of lake water quality. Nonetheless, the presence of heterogeneity implies that policy measures directed towards mire conservation would hardly be accepted in a consensus calling for the exploration of tailored local measures.

Across the discounting models we concluded that the hyperbolic specification performed better (under Mazur specification in particular), given the model fit statistics. Findings of previous studies are mixed with some studies providing evidence in favor of exponential discounting (e.g. Meyer 2013a, b) or evidence in favor of hyperbolic discounting (Grijalva et al. 2014; Vasquez-Lavín et al. 2019) or evidence in favor of both with no strong indications (Lew 2018).

A declining discount rate implies dynamic inconsistency in preferences and respondents that appear to be present-biased and thus more impatient for immediate benefit-cost trade offs. This may explain why according to summary statistics respondents were indifferent between lump sum and annual streams of payments even though annual payments would match with the duration of the benefits. Some possible explanation for the near-sighted behaviour of respondents is the difficulty of discounting and/or the inability of respondents to seriously consider the future streams of payments implied by the payment scheme (Myers 2017) that is regarded a temporal embedding problem similar to that of scope or scale embedding problems (Stevens et al. 1997).

When using a constant (exponential) discount rate function, we found an implied marginal discount rate of $13 \%$, while when assuming declining rates we found a rate in the 
range of $47-57 \%$ which decreases to almost $9 \%$ by the end of the payment period (i.e. in ten years). The substantial decline of discount rates in the long run is a desirable outcome particularly for our case specific study where the benefits are anticipated to be realized in the distant future and hence cost-benefit analysis should be extended further than the 10 years of time horizon.

Compared to former studies, our exponential and hyperbolic discount rate estimates are at the low end of some studies (e.g. Lew 2018; Wang and He 2018) as well as at the high end of other studies such as Bond et al. 2009 or Kim and Haab 2009 (Table 8, "Appendix"). High (low) discount rates can be justified by the short (long) time horizon of payments and hence a comparison of outcomes is only indicative. A full comparison is also difficult due to our population level approach. Integrating the timing of payment as a variable in future meta-analyses of empirical research could provide a comprehensive outline of the discounting behaviour findings, which, attached to certain approaches, could improve future CE design and interpretation of results.

Our results studying the discounting behaviour at a population level, rather than at individual level, raise a concern that survey respondents struggle with unassisted discounting. Offering multiple payment schedules with different time frames could maybe induce time consistent response behavior. Lacking comparative data to affirm this theory, we leave it for further studies.

Evidence of hyperbolic may involve confounding factors that reflect individuals' preference to care less about the future and which should not be mixed with pure time preferences. These factors include uncertainty about a future outcome, perceived future transaction costs and the phenomenon of subadditive discounting (Meyer 2013a). Payment structure insensitivity could also be related to attribute non-attendance and particularly to payment non-attendance. We found signs of payment non-attendance for the present CE study in Grammatikopoulou et al. (2019).

We conducted welfare analysis for different scenarios of peatland preservation and under different discounting model specifications. The lowest welfare estimate was anticipated when assuming hyperbolic discounting and the highest when assuming a constant discount rate. As noted in Lew 2018, a welfare analysis where future benefits and costs are involved and discount rate is either not estimated or is implied at a level commonly used for policy analysis (e.g., 3 or 7\%) may result to misleading conclusions. Considering our empirical findings we support this view and suggest that future CE studies should include discount rate estimations under different specifications or approaches, if possible. Devoid the chance to do this, the choice of payment vehicle remains a challenging one; the use of a lump sum would be free of determining a discount rate (Lew 2018) while the use of a stream of annual payments would most likely correspond to the benefit horizon (Egan et al. 2015).

Similar to Egan et al. (2015), we would like to stress the importance of clear exposition of the total payment over the payment horizon and reminders for the entire payment period. We suggest that both lump-sum and yearly payments should be considered and implemented in future CE so that WTP estimates from both versions can be further tested.

Several studies in the past have demonstrated the presence of heterogeneity in discount rate estimates suggesting that discount rate can be a function of socio-demographic factors such as age, gender, income and education (i.e. Bond et al. 2009; Grijalva et al. 2014; Richards and Greene 2015; Meyer 2013a, b) or can be randomly varied across individuals (Meyer 2013a, b). To this end, we also recommend using a variety of model specifications, including joint mixed logit models that account for both taste and scale heterogeneity as well as choice heuristics such as attribute non-attendance (as in Lew 2018). One approach 
to further delineate the heterogeneity of respondents concerning reactions to the timing of payment is latent class modelling which could provide more possibilities to illustrate the differences in WTP and discount rate estimates for respondent groups.

Acknowledgements We would like to acknowledge the Academy of Finland for the financial support in the ValuES project and Kaisu Aapala for her aid in mire descriptions in the questionnaire.

Funding Open access funding provided by Natural Resources Institute Finland (LUKE).

Open Access This article is licensed under a Creative Commons Attribution 4.0 International License, which permits use, sharing, adaptation, distribution and reproduction in any medium or format, as long as you give appropriate credit to the original author(s) and the source, provide a link to the Creative Commons licence, and indicate if changes were made. The images or other third party material in this article are included in the article's Creative Commons licence, unless indicated otherwise in a credit line to the material. If material is not included in the article's Creative Commons licence and your intended use is not permitted by statutory regulation or exceeds the permitted use, you will need to obtain permission directly from the copyright holder. To view a copy of this licence, visit http://creativecommons.org/licenses/by/4.0/.

\section{Appendix}

See Fig. 3 and Tables 8 and 9.

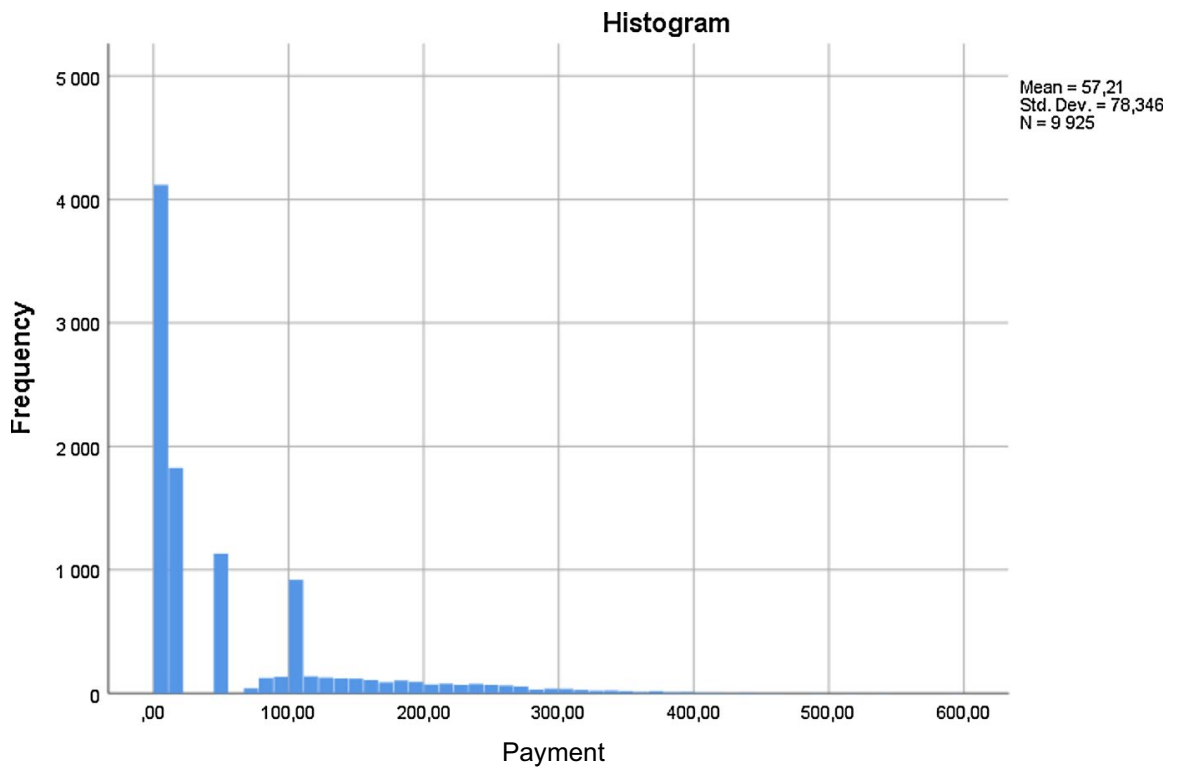

Fig. 3 Payment distribution after payment reconfiguration 


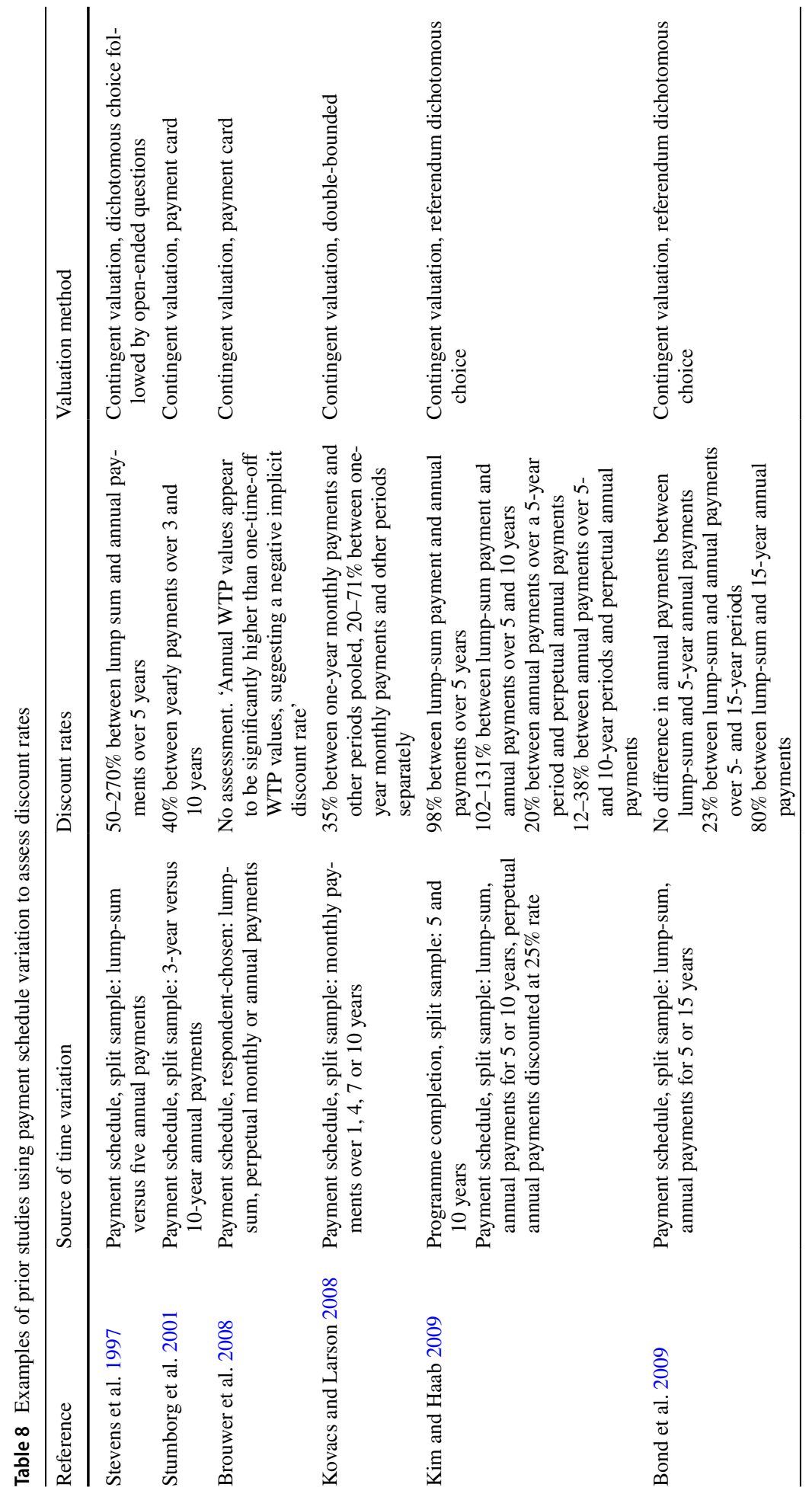




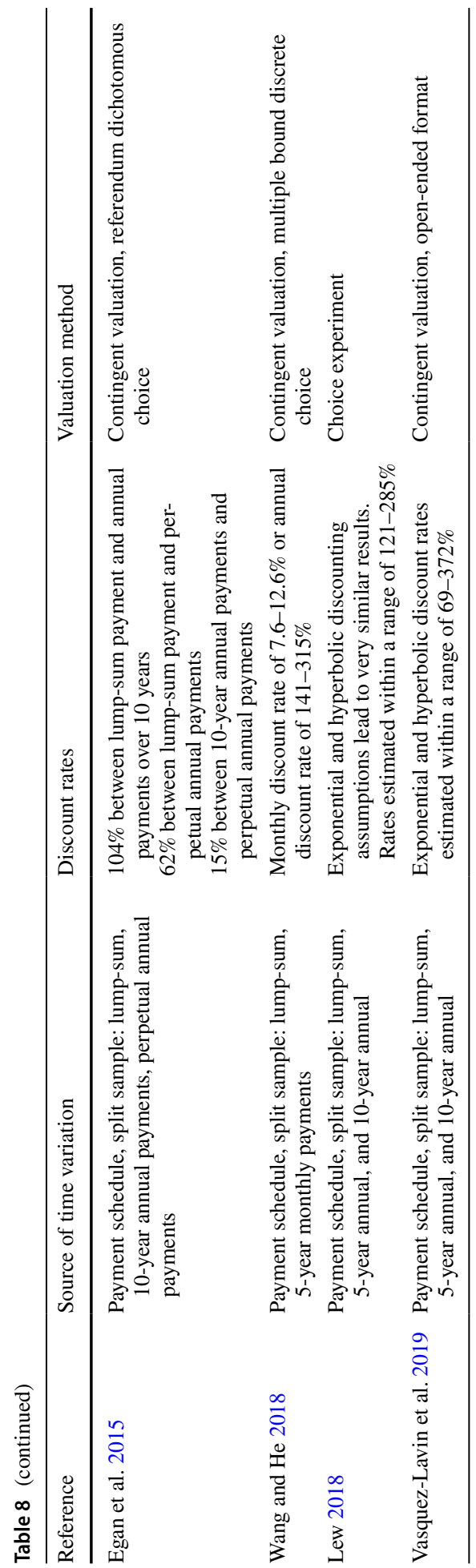


Table 9 Extensive version of mixed logit with interactions model

\begin{tabular}{|c|c|c|c|c|}
\hline Attributes & Coeff & Std.error & Std. dev & Std. error \\
\hline $\mathrm{ASC}_{\mathrm{SQ}}$ & $-1.324 * * *$ & 0.362 & $4.326^{* * *}$ & 0.187 \\
\hline Climate_M & $0.192 * * *$ & 0.053 & 0.032 & 0.088 \\
\hline Climate_H & $0.202 * * *$ & 0.055 & $0.233 * * *$ & 0.066 \\
\hline Peatland_M & $0.203 * * *$ & 0.050 & $0.191 * *$ & 0.083 \\
\hline Peatland_H & $0.589 * * *$ & 0.069 & $0.539 * * *$ & 0.043 \\
\hline Water_M & 0.009 & 0.052 & $0.213^{* *}$ & 0.067 \\
\hline Water_H & $0.602 * * *$ & 0.061 & $0.409 * * *$ & 0.047 \\
\hline Berry_M & $0.140^{* *}$ & 0.057 & $0.313^{* * *}$ & 0.054 \\
\hline Berry_H & 0.110 & 0.069 & $0.440^{* * *}$ & 0.047 \\
\hline Energy_M & $0.099 *$ & 0.056 & 0.004 & 0.059 \\
\hline Energy_H & $0.226 * * *$ & 0.058 & $0.395^{* * *}$ & 0.047 \\
\hline $\operatorname{Tax}$ & $-0.006^{* * *}$ & 0.000 & - & - \\
\hline Interactions (V1 as reference) & \multicolumn{4}{|c|}{ Heterogeneity around the mean } \\
\hline $\mathrm{ASC}_{\mathrm{SQ}} \times \mathrm{V} 2$ & $-1.709^{* * *}$ & 0.463 & - & - \\
\hline $\mathrm{ASC}_{\mathrm{SQ}} \times \mathrm{V} 3$ & $-0.875^{*}$ & 0.466 & - & - \\
\hline $\mathrm{ASC}_{\mathrm{SQ}} \times \mathrm{V} 4$ & $-1.357^{* *}$ & 0.460 & - & - \\
\hline Climate_M x V2 & 0.001 & 0.073 & - & - \\
\hline Climate_M x V3 & -0.028 & 0.074 & - & - \\
\hline Climate_M x V4 & $-0.141^{*}$ & 0.073 & - & - \\
\hline Climate_H x V2 & -0.077 & 0.077 & - & - \\
\hline Climate_H x V3 & -0.073 & 0.077 & - & - \\
\hline Climate_H x V4 & 0.032 & 0.075 & - & - \\
\hline Peatland_M x v2 & 0.009 & 0.069 & - & - \\
\hline Peatland_M x v3 & 0.002 & 0.070 & - & - \\
\hline Peatland_M x v4 & 0.024 & 0.069 & - & - \\
\hline Peatland_H x V2 & $-0.166^{*}$ & 0.089 & - & - \\
\hline Peatland_H x V3 & $-0.195 * *$ & 0.089 & - & - \\
\hline Peatland_H x V4 & $-0.314 * * *$ & 0.089 & - & - \\
\hline Water_M x V2 & -0.107 & 0.070 & - & - \\
\hline Water_M x V3 & -0.112 & 0.072 & - & - \\
\hline Water_M x V4 & -0.052 & 0.070 & - & - \\
\hline Water_H x V2 & $-0.251^{* *}$ & 0.081 & - & - \\
\hline Water_H x V3 & -0.125 & 0.083 & - & - \\
\hline Water_H x V4 & $-0.162 *$ & 0.081 & - & - \\
\hline Berry_M x V2 & -0.016 & 0.078 & - & - \\
\hline Berry_M x V3 & -0.043 & 0.080 & - & - \\
\hline Berry_M x V4 & -0.121 & 0.078 & - & - \\
\hline Berry_H x V2 & -0.045 & 0.095 & - & - \\
\hline Berry_H x V3 & 0.029 & 0.094 & - & - \\
\hline Berry_H x V4 & 0.110 & 0.092 & - & - \\
\hline Energy_M x V2 & -0.068 & 0.076 & - & - \\
\hline Energy_M x V3 & -0.031 & 0.079 & - & - \\
\hline Energy_M x V4 & -0.068 & 0.075 & - & - \\
\hline Energy_H x V2 & -0.108 & 0.078 & - & - \\
\hline
\end{tabular}


Table 9 (continued)

\begin{tabular}{llllc}
\hline Attributes & Coeff & Std.error & Std. dev & Std. error \\
\hline Energy_H x V3 & -0.106 & 0.079 & - & - \\
Energy_H x V4 & -0.115 & 0.078 & - & - \\
LL & -8703.081 & - & - & - \\
AIC & $17,518.2$ & - & - & - \\
R $^{2}$ & 0.339 & - & - & - \\
Sample size & 11,982 & - & - & - \\
\hline
\end{tabular}

The notation V1, V2, V3, V4 stands for payment version 1: lump sum, 2: 10 year annual no delay, 3:10 year annual 3 years delay and 410 year annual 6 years delay, respectively

*** $1 \%$ significance level, ** 5\% significance level, * $10 \%$ significance level

\section{References}

Andersson H, Hammitt JK, Lindberg G, Sundström G (2013) Willingness to pay and sensitivity to time framing: a theoretical analysis and an application on car safety. Environ Resource Econ 56:437-456

Bech M, Gyrd-Hansen D (2005) Effects coding in discrete choice experiments. Health Econ 14(10):1079_ 1083. https://doi.org/10.1002/hec.984

Birol E, Karousakis K, Koundouri P (2006) Using a choice experiment to account for preference heterogeneity in wetland attributes: the case of Cheimaditida wetland in Greece. Ecol Econ 60:145-156. https ://doi.org/10.1016/j.ecolecon.2006.06.002

Bond C, Giraud K, Larson D (2009) Joint estimation of discount rates and willingness to pay for public goods. Ecol Econ 68(11):2751-2759

Brouwer R, van Bukering P, Sultanian E (2008) The impact of the bird flu on public willingness to pay for the protection of migratory birds. Ecol Econ 64(3):575-585

Casey FJ, Kahn RJ, Rivas AFA (2008) Willingness to accept compensation for the environmental risks of oil transport on the Amazon: A choice modelling experiment. Ecol Econ 67:552-559

CICES (2016) CICES towards a common classification of ecosystem services. European environment agensy. http://cices.eu/. Accessed 4 Jan 2017

Colombo S, Hanley N, Louviere J (2009) Modelling preference heterogeneity in stated choice data: an analysis for public goods generated by agriculture. Agric Econ 40:307-322

Czajkowski M, Hanley N, LaRiviera J (2016) Controlling for the effects of information in a public goods discrete choice model. Environ Resource Econ 2016(63):523-544

Egan K, Corrigan J, Dwyer D (2015) Three reasons to use annual payments in contingent valuation surveys: convergent validity, discount rates, and mental accounting. J Environ Econ Manage 72:123-136

Freeman MC, Groom B (2014) Positively gamma discounting: Combining the opinions of experts on the social discount rate. Econ J 125:1015-1024

Grammatikopoulou I, Pouta E, Artell J (2019) Heterogeneity and attribute non-attendance in preferences for peatland conservation. Forest Policy Econ 104:45-55. https://doi.org/10.1016/j.forpol.2019.04.001

Grijalva TC, Lusk JL, Shaw WD (2013) Discounting the Distant Future: An Experimental Investigation. Environ Resour Econ 59(1):39-63. https://doi.org/10.1007/s10640-013-9717-0

Groom B, Hepburn C, Koundouri P, Pearce D (2005) Declining Discount Rates: The Long and the Short of it. Environ Resour Econ 32:445-493

Harvey CM (1986) Value functions for infinite-period planning. Manage Sci 32(9):1123-1139

Hensher D, Greene W (2003) The mixed logit model: the state of practice. Transportation 30(2):133-176

Hensher D, Rose J, Greene W (2015) Applied Choice Analysis. A Primer, vol 2. Cambridge University Press, New York

Kim S-I, Haab T (2009) Temporal insensitivity of willingness to pay and implied discount rates. Resource Energy Econ 31(2):89-102

Kaakinen E, Kokko A, Aapala K, Kalpio S, Eurola S, Haapalehto T, Heikkilä R, Hotanen J-P, Kondelin H, Nousiainen H, Ruuhijärvi R, Salminen P, Tuominen S, Vasander H, Virtanen K (2008) Suot (Mires). In Suomen luontotyyppien uhanalaisuus-Osa I: Tulokset ja arvioinnin perusteet (Assessment of threatened habitat types in Finland-Part 1: Results and basis for assessment). The Finnish Environment 8/2008. Eds. Raunio, A., Schulman, A., Kontula, T. The Finnish Environment Institute. p 264 (in Finnish)

Karp L (2005) Global warming and hyperbolic discounting. J Publ Econ 89:261-282 
Karp L, Tsur Y (2011) Time perspective and climate change policy. J Environ Econ Manage 62:1-14

Kosenius A (2010) Heterogeneous preferences for water quality attributes: the case of eutrophication in the Gulf of Finland. Baltic Sea Ecol Econ 69:528-538

Kovacs K, Larson D (2008) Identifying individual discount rates and valuing public open space with statedpreference models. Land Econ 84:209-224

Lew DK (2018) Discounting future payments in stated preference choice experiments. Resour Energy Econ 54:150-164. https://doi.org/10.1016/j.reseneeco.2018.09.003

Loewenstein G, Prelec D (1992) Anomalies in intertemporal choice: evidence and an interpretation. Q J Econ 107(2):573-597

Mazur JE (1987) An adjustment procedure for studying delayed reinforcement. In: Commons ML, Mazur JE, Nevin JA, Rachlin H (eds) QuantitativeAnalysis of Behaviour: the Effect of Delay and Intervening Events on Reinforcement Value. Erlbaum, Hillsdale, New Jersey, pp 55-73

McFadden D (1974) Conditional logit analysis of qualitative choice behavior. In: Zarembka P (ed) Frontiers in econometrics. Academic Press, New York, pp 105-142

McFadden D, Train K (2000) Mixed MNL models for discrete response. J Appl Econ 15(5):447-470

Metsähallitus, State Forest Enterprise 2016. Restoration of Mire Ecosystems in Finland. https://www.metsa .fi/web/en/mirerestoration (accessed 4.1.2017)

Meyer A (2013b) Estimating discount factors for public and private goods and testing competing discounting hypotheses. J. Risk Uncertain. 46, 133-173.Meyer, A., 2013b. Intertemporal valuation of river restoration. Environ Resour Econ 54:41-61

Meyer A (2013b) Intertemporal valuation of river restoration. Environ Resour Econ 54:41-61

Myers K, Parsons G, Train K (2017) Inadequate response to frequency of payments in contingent valuation of environmental goods. In: Mcfadden D, Train K (eds) Chapter 3 in Contingent Valuation of Environmental Goods: A Comprehensive Critique. Edward Elgar, Northampton, pp 43-57

Parsons GR, Myers K (2016) Fat tails and truncated bids in contingent valuation: an application to an endangered shorebird species. Ecol Econ 129:210-219. https://doi.org/10.1016/j.ecolecon.2016.06.010

Richards TJ, Green GP (2014) Environmental choices and hyperbolic discounting: an experimental analysis. Environ Resource Econ 62(1):83-103. https://doi.org/10.1007/s10640-014-9816-6

Prime Minister's Office 2015. Finland, a land of solutions - Strategic Programme of Prime Minister Juha Sipilä's Government. Government Publications 12/2015. https://valtioneuvosto.fi/documents/10184 /1427398/Ratkaisujen+Suomi_EN_YHDISTETTY_netti.pdf/8d2e1a66-e24a-4073-8303-ee3127fbfc ac/Ratkaisujen+Suomi_EN_YHDISTETTY_netti.pdf.pdf

Rose JM, Bliemer MCJ (2009) Constructing efficient stated choice experimental designs. Trans Rev 29:597-617

Stevens T, DeCoteau N, Willis C (1997) Sensitivity of contingent valuation to alternative payment schedules. Land Econ 73(1):140-148

Stumborg B, Baerenklau K, Bishop R (2001) Nonpoint source pollution and present values: a contingent valuation study of Lake Mendota. Rev Agric Econ 23(1):120-132

Taloustutkimus (2017) Internet panel. https://www.taloustutkimus.fi/in-english/products_services/internet_ panel/. Accessed January 25. 2017

Train K (1998) Recreation demand models with taste differences over people. Land Econ 74(2):230-239

Train K (2003) Discrete choice methods with simulation. Cambridge University Press, New York

Vasquez-Lavín F, Ponce Oliva RD, Hernández JI, Gelcich S, Carrasco M, Quiroga M (2019) Exploring dual discount rates for ecosystem services: evidence from a marine protected area network. Resour Energy Econ 55:63-80. https://doi.org/10.1016/j.reseneeco.2018.11.004

Viscusi WK, Huber J, Bell JJ (2008) Estimating discount rates for environmental quality from utility-based choice experiments. Risk Uncertain 37:199-220

Wang H, He J (2018) Implicit individual discount rate in China: A contingent valuation study. J Environ Manage 210:51-70. https://doi.org/10.1016/j.jenvman.2017.12.058

Publisher's Note Springer Nature remains neutral with regard to jurisdictional claims in published maps and institutional affiliations. 